\title{
A PROTEÇÃO DO CONHECIMENTO TRADICIONAL NO CONTEXTO DA GLOBALIZAÇÃO DO DIREITO*
}

\section{THE PROTECTION OF TRADITIONAL KNOWLEDGE IN THE CONTEXT OF GLOBALIZATION OF LAW}

\author{
Joaquim Shiraishi Neto**
}

\section{Introdução}

Em 05 de junho de 2012, o Ministério de Meio Ambiente (MMA) e o Ministério das Relações Exteriores (MRE) submeteram ao Congresso Nacional - por meio da Mensagem $245^{1}$-, o texto do "Protocolo de Nagoya sobre Acesso a Recursos Genéticos e Repartição Justa e Equitativa dos Benefícios Derivados de sua Utilização à Convenção sobre Diversidade Biológica (CDB)"2, concluído no período da $10^{\circ}$ Conferência das Partes na Convenção (COP-10).
O Protocolo de Nagoya é um documento suplementar à CDB, tendo esse Tratado delineado diretrizes e objetivos gerais ao acesso aos recursos genéticos, conhecimento tradicional e repartição justa e equitativa de benefícios. Para Manuela Carneiro da Cunha (2009), os recursos genéticos eram considerados patrimônio comum da humanidade, por isso o acesso era livre, sem restrições.

Como a inexistência de regulamentação jurídica facilitava a concentração da riqueza em mãos dos detentores de tecnologias, não houve surpresa na postura de representantes

\footnotetext{
* Este artigo foi escrito no âmbito do Projeto de Pesquisa: "A Commoditização da Natureza no Brasil: as leis ambientais fundamentadas nos discursos das Instituições Financeiras, Agências de Cooperação e Organizações Internacionais", com apoio da Fundação de Amparo à Pesquisa e ao Desenvolvimento Científico e Tecnológico do Maranhão [FAPEMA (Edital 040/ 2015)].

** Professor visitante da Universidade Federal do Maranhão - UFMA - (São Luís/MA/BR), vinculado ao Programa de Pós-graduação em Ciências Sociais. Pesquisador FAPEMA e CNPQ. Bolsista Produtividade em Direito. E-mail: shiraishineto@gmail.com.

1. Em 31 de março de 2015, o presidente da Câmara dos Deputados criou uma Comissão Especial destinada a proferir Parecer à Mensagem no 245, de 2012.

2. 0 Decreto 2.519, de 16 de março de 1998, "promulga a Convenção sobre Diversidade Biológica", assinada no Rio de Janeiro, em 05 de junho de 1992.
} 
que tinham a CDB como um instrumento de "justiça distributiva". Os esforços em reforçar tais ideais se difundiam: "[...] the CDB has the most part become an instrument which crystallizes dreams of planetary equity and hopes of economic prosperity, founded on the use of 'green gold' from which it is envisage that biotech industries will develop the medicines of tomorrow". (AUBERTIN; FILOCHE, 2011, p.52 - grifos nossos).

No Brasil, antes mesmo da existência do Protocolo de Nagoya, em junho de 2000, o governo federal, em meio a uma controvérsia gerada pelo Acordo Bioamazônia Novartis Pharma AG, publicou, às pressas, a Medida Provisória 2.052, cuja última reedição foi a Medida Provisória 2.186-16, de 23 de agosto de $2001^{3}$. Os trabalhos de Derani (2002), Araújo (2002), Santilli (2005), Moreira (2007) e Shiraishi Neto e Dantas
(2010), dentre tantos, foram contribuições relevantes no período, pois cada uma à sua maneira, promoveram reflexões, auxiliando as discussões em torno efetivação da Medida Provisória 2.186-16/2001.

Tal Medida foi revogada por um novo marco legal, a Lei 13.123, de 20 de maio de $2015^{4}$, objeto de reflexão neste artigo, elaborada e proposta pelo governo federal ao Congresso Nacional a pedido das indústrias químicas, alimentícia e de cosméticos ${ }^{5}$, em regime de urgência constitucional ${ }^{6}$, sob a conformação do Protocolo de Nagoya. 0 "regime de urgência" do Projeto de Lei 7.735/2014, apresentado pelo governo federal, gerou contestações por parte da sociedade civil organizada, já que tal expediente estaria ferindo o direito de consulta prévia, livre e informada, consagrado na Convenção n.169, da Organização Internacional do Trabalho (OIT) .

3. "Regulamenta o inciso II do $\$ 4^{\circ}$ do art. 225 da Constituição, os arts. $1^{\circ}$ e $8^{\circ}$, alínea “j”, 10, alínea "c”, 15 e 16, alíneas 3 e 4 da Convenção sobre a Diversidade Biológica, dispõe sobre o acesso ao patrimônio genético, a proteção e o acesso ao conhecimento tradicional associado, a repartição de benefícios e o acesso à tecnologia e transferência de tecnologia para sua conservação e utilização, e dá outras providencias." 4. "Regulamenta o inciso II do $\$ 1^{\circ}$ e o $\$ 4^{\circ}$ do art. 225 da Constituição Federal, o artigo $1^{\circ}$, alínea "j", do artigo $8^{\circ}$, a alínea “c”, do artigo 10, o artigo 15 e os $\$ \$ 3^{\circ}$ e $4^{\circ}$, do artigo 16 da Convenção sobre Diversidade Biológica, promulgada pelo Decreto 2.519, de 16 de março de 1998; dispõe sobre o acesso ao patrimônio genético, sobre a proteção e o acesso ao conhecimento tradicional associado e sobre a repartição de benefícios para conservação e uso sustentável da biodiversidade; revoga a Medida Provisória 2.186-16, de 23 de agosto de 2001; e dá outras providências."

5. Segundo reportagem publicada pelo Jornal Valor Econômico, o Projeto de Lei foi apresentado pelo governo “[...] após pressão das indústrias química, alimentícia e de cosméticos para facilitar a pesquisa sobre a biodiversidade para desenvolvimento de produtos e renegociar multas a empresas e instituições que enviaram amostras para fora do País sem autorização ou fizeram pesquisa sem pagar royalties." (HOUVE retrocesso na biodiversidade, critica WWF. Rio de Janeiro: Jornal Valor Econômico, 29/04/2015. Disponivel em https://www.valor.com.br/politica/4026720/houve-retrocesso-na-biodiversidade-critica-wwf. Acesso em 19 de março de 2019).

6. 0 regime de urgência impõe prazos menores para a tramitação da proposta apresentada, 45 dias para cada casa, sob pena de sobrestar todas as demais deliberações legislativas. No caso, a copa do mundo e as eleições contribuíram com a diminuta participação e discussão no Congresso Nacional.

7. Sobre essa polemica gerada em torno do descumprimento do direito, recomendamos o documento (Ministério Público Federal. Recomendações. Brasília, 25 de junho de 2015. Referência: IC 1. 
Este artigo objetiva analisar a Lei $13.123 / 2015$, que se encontra inserida na lógica da globalização do direito, mais precisamente, da globalização do direito americano. A pretexto da necessidade de reformar a Medida Provisória 2.186/2001, aquela Lei "modificou” a proteção, o acesso e a repartição dos benefícios derivados do conhecimento tradicional. Tratando esse conhecimento como objeto- mercadoria, a Lei nega aos mais diferentes povos e comunidades tradicionais direitos diante dos distintos "modelos de natureza” (ESCOBAR, 2005) construídos por esses grupos, ao longo de sua história.

A metodologia se baseou no levantamento e análise de dados de fontes secundárias, como documentos, tratados - especificamente: a Convenção sobre a Diversidade Biológica e Protocolo de Nagoya -, e o Projeto de Lei, apresentado em regime de urgência pelo governo ao Congresso Nacional.

Para cumprir o objetivo proposto, o artigo está dividido nas seguintes partes: "Reestruturação do Campo Jurídico no Brasil: o direito como negócio", com o objetivo analisar a produção do direito a partir da noção de campo jurídico, que hoje se encontra internacionalizado. Ao mesmo tempo, destaca o papel do direito na legitimação dessa nova ordem econômica, financeirizada.

0 tópico intitulado "Homogeneização Jurídica': agências e instituições no comando da construção de uma nova ordem jurídica nacional de proteção da natureza" analisa a participação de agentes externos aos Estados - nacionais na produção de um novo direito da natureza, sendo inegável que o conteúdo único atribuído a ela nega os "modelos de natureza" vividos no Brasil. Trata-se de fazer uma reflexão sobre os processos impostos pela ordem econômica global, que provoca sucessivos deslocamentos da política ambiental brasileira (da "sustentabilidade" à "gestão" ambiental). Finalmente, o último tópico “A Lei 13.123/2015 sob orientação do Protocolo de Nagoya: o conhecimento tradicional associado à biodiversidade como objeto/mercadoria" detalha o contexto da produção da Lei que modificou a Medida Provisória 2.186/2001.

\section{Reestruturação do campo jurídico no Brasil: o direito como negócio}

Nas faculdades de direito sempre houve uma preocupação dos professores em ensinar que o direito se constitui num sistema fechado e autônomo, embora fique evidente, em tempos recentes, os esforços da hermêutica jurídica em integrar o sistema, entendido como aberto, capaz de uma maior interação com o mundo social. Recorremos à Miaille (1977) sobre uma crítica à forma segundo a qual é introduzido o direito aos estudantes. Apesar do texto ter sido escrito já há algum tempo mantém a sua atualida-

16.000.001457/2015-19). O MPF foi um dos primeiros órgãos a se manifestar questionando a proposta apresentada pelo governo. Aconselhamos também Nota Técnica Jurídica elaborada por várias organizações (Terra de Direitos, Via Campesina do Brasil, Movimento dos Pequenos Agricultores, Movimento de Mulheres Camponesas, GT - Biodiversidade da Articulação Nacional de Agroecologia, Instituto Socioambiental) sobre os termos da Lei (Terra de Direitos et. al., 2015). Na ocasião, a FIOCRUZ se manifestou trazendo contribuições ao Projeto. 
de. Ele aponta a simplicidade que marca os cursos de introdução ao direito, a partir da transmissão de definições a priori, da naturalidade das classificações jurídicas e das técnicas de interpretação, escondendo uma pretensa neutralidade do direito.

Essa forma de ensinar o direito, fundamentada em um entendimento meramente formal do que seja o direito, assim como as críticas formuladas pelos marxistas, que concebem o direito como um instrumento a serviço das classes dominantes, ignora um dado central para compreender o funcionamento, isto é, os fundamentos sociais de sua autonomia, conexa à capacidade de produzir e reproduzir um corpus jurídico independente de constrangimentos de onde se exerce a autoridade jurídica, força por excelência da violência simbólica (BOURDIEU, 1989) ${ }^{8}$.

A ideia de autonomia do direito, atualizada na expressão império do direito, representa uma maneira de afırmar a existência de uma ordem normativa independente da sociedade (DELAZAY e TRUBEK, 2010). Tal interpretação corrobora a difusão de outra ideia cara ao direito, o seu caráter de neutralidade, cuja função precípua é legitimar o exercício do poder. Lembram Delazay e
Garth (2002; 2005) que o direito fornece uma linguagem-chave de legitimação.

Os discursos e as práticas jurídicas, enquanto produtos de um espaço específico, são denominados por Bourdieu de campo jurídico:

O campo jurídico é o lugar de concorrência pelo monopólio do direito de dizer o direito, quer dizer, a boa distribuição (nomos) ou da boa ordem, na qual se defrontam agentes investidos de competência ao mesmo tempo social e técnica que consiste essencialmente na capacidade reconhecida de interpretar (de maneira mais ou menos livre ou autorizada) um corpus de textos que consagram a visão legitima, justa, do mundo social. (BOURDIEU, 1989: p. 212 - grifos nossos)

Yves Dekazay e David M. Trubek denominam de “[...] campo jurídico à articulação de instituições e práticas através das quais a lei é produzida, interpretada e incorporada às tomadas de decisões na sociedade" (DELAZAY e TRUBEK, 2010, p. 31).

Com a globalização econômica, forças e lógicas estranhas ao espaço nacional interferem no campo jurídico nacional ${ }^{9}$, que está

8. Se bem que no Brasil, a politização do direito pela própria atuação do Poder Judiciário mina esse dogma. 0 trabalho de juízes em perseguir determinadas lideranças políticas, escolhidas por eles como "inimigas" da sociedade, colocam em questão todo o ideário construído em torno do papel do Poder Judiciário. Na semana do julgamento do ex-presidente Luiz Inácio Lula da Silva pelo TRT 4 eram fartas as reportagens sobre o Poder Judiciário, que tem politizado os seus julgamentos. Dentre tantas, sugerimos a de Rodrigo Martins, publicada na Revista Carta Capital, intitulada: "Os Políticos de Toga. 0 julgamento de Lula é a expressão máxima da Justiça politizada, a retirar do povo o poder de decidir sobre o seu próprio destino." Especificamente sobre esse caso envolvendo o julgamento do ex-presidente Lula, indicamos também o livro organizado por Carol Porter et. all. (2017).

9. A noção de campo jurídico foi utilizada por Shiraishi Neto (2008) para compreender a produção de uma verdade sobre o direito de propriedade privada no Brasil. Analisei o papel das editoras, que através dos manuais de Direito Real, produzem e disseminam representações sobre a propriedade privada. 
se internacionalizado, já que atravessado por outras práticas jurídicas ${ }^{10}$, notadamente, aquelas ditadas pelo direito norte-americano (DELAZAY e GARTH, 2005) ${ }^{11}$. A noção de campo jurídico de Pierre Bourdieu, aqui utilizada, possibilita deslocar o foco de análise para a ação dos sujeitos (legisladores, advogados, juízes, procuradores, professores...), que se ocupam da produção, reprodução e difusão do direito. Esse exercício, contudo, não ignora as questões estruturais e funcionais do direito, que dominam as reflexões jurídicas.

A globalização do direito, mais especificamente, a globalização do direito americano, como é designado, que está a (re)estruturar as estruturas objetivas e subjetivas dos campos jurídicos nacionais, é um fenômeno recente no Brasil, diferentemente da Europa que vive esse processo há algum tempo ${ }^{12}$. Na Europa, a divisão do trabalho jurídico que era fortemente hierarquizada entre "[...] aqueles que praticavam o direito e aqueles que o produziam e o interpretavam [...]" (DELAZAY e TRUBEK, 2010, p.42) se transformou, na medida em que a prestação de serviços jurídicos é direcionada aos negócios. A prestação de serviços na defesa dos direitos humanos, considerada de "interesse público", é também digna de nota, pois faz parte do modelo de produção do direito norte-americano, exportado para o mundo. Los mandararines del derecho foi o termo utilizado por Bonilla Maldonado (2017) para designar a expansão do modelo transnacional de proteção dos direitos humanos nos países latino-americanos ${ }^{13}$.

0 uso da literatura jurídica norte-americana no ensino e na aplicação do direito e a "invasão estrangeira" ${ }^{14}$ de escritórios de advocacia americanos desde $2008^{15}$, se constituem em episódios recentes, sinalizan-

10. Os direitos nacionais sempre sofreram influências de outros modelos a pretexto de melhorá-los. No caso do Brasil, inúmeros exemplos podem ser trazidos à coleção. As primeiras faculdades de direito no Brasil, Olinda e São Paulo, sofreram influências do pensamento jurídico europeu. 0 "darwinismo jurídico" foi útil aos interesses dominantes, pois contribuiu com a estruturação de um modelo autoritário e racista de sociedade. A este respeito, Schwarcz (1993).

11. As transformações jurídicas produzem formas complexas de "pluralismo jurídico" (FARIAS, 2002), os quais não serão objeto de reflexão neste artigo. 0 trabalho de André-Jean Arnaud (1999), por sua vez, nos foi útil, pois serviu como ponto de partida às reflexões: "Os problemas de regulamentação e de controle se colocam de forma aguda e totalmente nova. Vemos desenvolver-se à margem de um direito de feição tradicional, princípios, estratégias e normas de gestão da regulação que são reconhecidas por todo planeta. Uma tal perturbação não se dá sem colocar numerosos problemas aos juristas." (ARNAUD, 1999, p. 19 - grifos nossos). 12. Na Europa, esses processos ocorrem de maneira diferenciada nos países, como bem destacou Marcos Nobre (2003) a partir das pesquisas de David M. Trubek.

13. Neste contexto da globalização do direito, Boaventura de Sousa Santos (1999) chama atenção para a expansão dos direitos humanos ligados aos "novos atores sociais". Em trabalhos mais recentes sobre esse fenômeno de expansão dos direitos humanos, Boaventura e Cesar Rodrigues Garavito (2007) focalizam os aspectos locais, "desde abajo."

14. A respeito da "invasão estrangeira" de escritórios estrangeiros no Brasil, aconselhamos a leitura da reportagem de Thiago Bronzatto publicada na Revista Exame (2010).

15. 0 post publicado por Luís Nassif (2017) expõe o papel de escritórios de advocacia americana, como parte das estratégias que movem os interesses norte-americanos no Brasil. Escritórios ligados ao Departamento de Estado e Departamento de Justiça funcionam como braço do governo americano, "[...] atuando em alinhamento com ele na proteção dos interesses essenciais dos EUA.” 
do para as mudanças do campo jurídico no Brasil, ou melhor, para as transformações no "modo de produção do direito", que institui “novas verdades jurídicas” independentemente dos contextos em que são produzidas.

Tais estratégias do imperialismo americano em "universalizar particularismos" (BOURDIEU e WACQUANT, 1998), importam em transformações da sociedade. Guerras palacianas expressam esses movimentos estratégicos que se constituem em lutas não apenas pelo controle do Estado, mas também pelos valores relativos dos indivíduos e dos conhecimentos que dão forma e direção ao Estado (DELAZAY e GARTH, 2002).

Os "mecanismos alternativos de solução de conflitos", designados ADR ("Alternativa Dispute Resolutions”), que foram instituídos no Brasil, com a reforma do Código de Processo Civil, na forma da mediação, arbitragem e conciliação, rebatem de forma eficaz na organização da vida social. Apresentados como alternativas às resoluções de conflitos, dado o seu alto grau de eficiência, racionalidade, modernidade... esses produtos acabam interferindo na estruturação da cultura das sociedades (NADER, 1994).

Os mecanismos alternativos, originados nos EUA e espalhados pelo mundo, como "alternativa aos mecanismos de solução de conflitos”, instituem uma nova forma de convivência nas sociedades ao produzir "novos sujeitos", intolerantes aos conflitos e complacentes com acordos, negociações e conchavos.

Os estudos da antropóloga Laura Nader (1994), envolvendo a instituição desses aludidos mecanismos pelo mundo, nos alertam para a sua gravidade, já que são absolutamente nocivos aos desprovidos de poder, embora disseminem a ideia de que todos ganham win or win, na verdade, os grupos se vêem na obrigação de negociar direitos imprescindíveis à sua reprodução, tal como observado nas inúmeras situações estudadas pela autora.

Como efeito, trata-se de processos que vão além da simples alteração da forma de resolução de conflitos. Segundo Francisco de Oliveira, para esse modelo de sociedade, onde imperariam a harmonia e a paz (acrescentamos, o direito), o cidadão seria aquele avesso a toda forma de conflito, portanto, destituído de sua própria condição de cidadão (OLIVEIRA, 2002). Nas situações envolvendo os grupos definidos por critérios étnicos ou por particularidades em seu modo de vida e relação com o ambiente biofísico, a negação dos conflitos implica na destituição de suas falas, consequentemente, de sua identidade, muitas vezes ainda em construção (SHIRAISHI NETO, 2015). Em outras palavras, a ideia do "consenso" ou do "direito negociado" afasta qualquer possibilidade de garantia e aplicação dos direitos fundamentais inscritos na Constituição Federal de 1988, sobretudo se esses direitos estão involucrados nos próprios sujeitos que pertencem a determinados povos e comunidades conceituadas como tradicionais.

Em países como o Brasil, as transformações na ordem jurídica ditadas pela globalização do direito, envolvendo o deslocamento dos estados fundados no bem estar para estados liberais (DELAZAY e GARTH, 2002) é central para a compreensão do que ocorre no país, cujo desfecho mais violento, foi o golpe parlamentar, jurídico e midiático que destituiu uma presidenta legalmente eleita. 0 golpe sacralizou no Brasil a perda da posição do Estado de supremacia na estruturação e regulamentação jurídica das relações econômicas e na proteção dos indivíduos e sociedade.

Os trabalhos de pesquisa de Gilberto 
Bercovici (2004; 2008) nos auxiliam na compreensão do processo que culminou com a instalação do "Estado de Exceção" no Brasil. Assevera o autor que o "estado de exceção econômica” se tornou regra desde os tempos do governo Fernando Collor de Mello, com ataques à Constituição de 1988, que destrói o regime constitucional (BERCOVICI, 2008). As reformas no texto constitucional, nos sucessivos governos, modificaram substancialmente o conteúdo da Constituição Federal de 1988, caracterizada por conter um ambicioso programa social pautado na promoção da dignidade da pessoa humana, princípio esse organizador e estruturante de todas as políticas públicas.

Passa a estar em jogo no país a dissolução da "velha ordem jurídica", recheada de um catálogo de direitos sociais edificados a partir da Constituição Federal de 1988. Não se trata, contudo, do "fim do direito", mas sim de um direito: "[...] 0 ideal do direito social foi eliminado, substituído pela lex mercatoria: o direito internacional das relações comerciais." (DELAZAY, 1999, p. 296), na medida que essa nova ordem jurídica, renovada, proporciona uma melhor assistência a seus clientes ao criar formulas jurídicas adequadas à expansão econômica do capital financeiro.

A interconexão entre os sistemas legais nacionais e a homogeneização jurídica (DELAZAY, 1999) favorecem o "modo de produção do direito norte-americano”. Enquanto resultado de um trabalho sistemático realizado por canais supostamente neutros, think tanks, agências de cooperação internacional, instituições financeiras, passar a desempenhar papel decisivo nos processos que determinarão as reformas.

A homogeneização jurídica longe de se constituir em algo natural relacionado à evolução/modernização dos sistemas ju- rídicos pelo mundo, trata-se de uma imposição, no sentido de que a unificação beneficia aqueles que estão em melhores condições econômicas. No tópico abaixo, nos concentramos na análise do papel das agências de cooperação e instituições financeiras no comando da ordem jurídica nacional que, sob influência de regimes e ordens jurídicas transnacionais, supranacionais e internacionais, contaminam a criação de novos marcos legais no Brasil, os quais afetam as representações e o conteúdo jurídico da natureza.

2. "Homogeneização Jurídica": agências e instituições no comando da construção de uma nova ordem jurídica nacional de proteção da natureza

A Lei 13.123/2015, que revogou a Medida Provisória 2.186-16, de 23 de agosto de 2001, deve ser compreendida no contexto da globalização do direito.

A noção de homogeneização jurídica (BOURDIEU, 2001) apresentada como um indício positivo da globalização econômica, nos permite compreender como ocorre a operacionalização desse projeto de sociedade, determinado pelos interesses econômicos, situados acima dos estados nacionais. Entre os pesquisadores do direito (FARIAS, 2002; ARNAUD, 1999), há um consenso de que a globalização econômica vem transformando o direito tal como concebido originariamente, delimitado aos espaços do Estado-nação. A construção de uma unidade jurídica denominada de "harmonização", envolve o efetivo funcionamento de uma economia globalizada que se impõe a todos países.

A homogeneização jurídica se constitui na produção e difusão de dispositivos (normas, procedimentos e estruturas) pelo 
mundo a partir de uma experiência absolutamente particular (envolvendo estratégias do imperialismo dos EUA, como mencionado acima), cujos propósitos se vinculam às garantias da livre circulação de bens, serviços, pessoas e do próprio capital.

Em termos práticos, do ponto de vista dos operadores do direito, isto é, dos grandes escritórios de advocacia americano associados a vários outros pelo mundo, tal homogeneização representa um maior controle sobre a produção, a difusão e a circulação do direito ou sobre, "o direito em dizer o direito”. Mais precisamente, a universalização dos dispositivos possibilita controle das decisões judiciais independentemente dos contextos sociais. Da cidade do México à São Paulo e de São Paulo à Jacarta, na Indonésia, um mesmo padrão jurídico, que facilita a atuação dos escritórios de advocacia norte-americanos. No caso, a língua deixa de ser uma barreira.

Desta forma, conforme esclarece Bourdieu, esse processo determinado pelo campo econômico vem reduzindo as proteções jurídicas tradicionais, levando os sujeitos (acrescentamos, os povos e as comunidades tradicionais no Brasil) a ficar desprotegidos. Os direitos fundamentais outrora outorgados passam ser flexionados, no sentido de que representam obstáculos a essa nova ordem (BERCOVICI, 2008).

Os discursos jurídicos avaliadores da necessidade da universalização dos dis- positivos se referem a um conjunto de argumentos. Além dos valores de liberdade e democracia, exaustivamente difundidos como inerentes a esse projeto de socieda$\mathrm{de}^{16}$, que, per si, são tidos como justificando as medidas, gostaríamos de focalizar outras duas noções alegadas para impor celeridade às reformas: segurança jurídica e tempo do direito.

A segurança jurídica e seu corolário, a insegurança, justificam, no caso do PL 7.735/2014 (que originou a Lei 13.123/2015), a reforma da MP 2.18616/2001, tida como necessária à preservação da sociobiodiversidade e à geração de recursos para o desenvolvimento do Brasil. A ideia da segurança jurídica, sublinha-se, sempre esteve travestida no direito, pois o discurso jurídico a vinculava às garantias de proteção dos direitos individuais quando, na verdade, ela opera para garantir os direitos de propriedade privada.

A imediaticidade da reforma da MP (no caso, o regime de urgência do PL), por outro lado, está referida à insegurança jurídica decorrente da alegada insuficência da MP 2.186/2001 para atender as demandas das indústrias químicas, alimentícia e de cosméticos. A insegurança, destaca Ranciere (2005), é imprescindível para manter o bom funcionamento do Estado, na medida em que ela serve para eliminar os conflitos e gerar consenso em torno das proposições.

Apesar de a insegurança ser utilizada

16. A propósito de uma consistente crítica à sociedade norte-americana, que organizou um poderoso controle social dos negros através de um complexo sistema prisional que encarcera esses grupos, recomendamos o documentário $13^{\text {a }}$ Emenda, disponível na NETFLIX. Sugerimos, também, o livro The New Jim Crow: Mass Incarceration in the Age of Colorblindness, de Michelle Alexander, publicado no Brasil sob o título A Nova Segregação: Racismo e encarceramento em massa (2017). 
por Ranciere em outro contexto, o "sentimento de insegurança” é indispensável, uma vez que ele justifica a produção dos novos dispositivos que se encontram em sincronia com os fluxos de capital, que intensificam as trocas pelo mundo. Ouvir os povos e comunidades tradicionais, tal como determina a Convenção 169, da Organização Internacional do Trabalho (OIT), no caso, se constituiria em mero detalhe, mediante os argumentos perfilados acerca do papel da sociobiodiversidade na preservação e geração de recursos ao país.

Na globalização, o tempo do mercado e o "tempo do direito" se apresentam como irmãos siameses. Indissociados, mercado e direito operam na construção de uma unidade econômica global.

0 tempo do direito, pelo visto, é incapaz de discernir as temporalidades e axiologias existentes nas diversas sociedades a revelar distintos "modelos de natureza". Mais do que isso, o tempo do direito produz e dissemina outra ideia cara a esse projeto de sociedade, de que os direitos (e os sistemas de justiças e instituições que se vinculam a esses direitos) se encontram em etapas evolutivas distintas de desenvolvimento, assim, a "modernização" é a palavra-chave. Sabiamente manejada, ela possibilita a disseminação das ideias pelo mundo, a exemplo do que ocorreu em outros períodos coloniais. Em contexto do pós-colonialismo, o direito é a chave para todo tipo de violência.
As reformas do poder judiciário na América Latina e Caribe patrocinadas pelo Banco Mundial (BIRD) ${ }^{17}$ são exemplos paradigmáticos da homogeneização jurídica que impõe uma feição única ao poder judiciário. Cabendo-lhe garantir estabilidade para um melhor funcionamento dos mercados. Não somente o Banco Mundial, mas também diversas outras agencias de cooperação internacional se tornaram protagonistas na difusão de projetos e programas alinhados a esse receituário neoliberal. Carbonell e Vazquez (2007) rememoram seu papel marcante na definição de políticas públicas que afetam o cotidiano dos indivíduos e de coletividades nas sociedades contemporâneas. "Hoy em día se tiene la percepeción de que
las instituciones internacionales tien poco
que ver com la vida cotidiana o con las ex-
presiones políticas de la gente, cuando lo
cierto es todo lo contrario. Una buena parte
de las politicas públicas que afectan las acti-
vidades cotidianas de la gente se instrumen-
tan a partir de decisiones tomadas em sede no
nacionales; además de que, como es evidente,
las instituciones internacionales se mantie-
nen con dinero proveniente de los impuestos
que todos pagamos, con lo cual nos instala-
mos em uma visión pós-moderna del taxa-
tion without representation." (CARBONELL e
VÁZQUEZ, 2007, p. 12-13 - grifos nossos).

17. A respeito, sugerimos a leitura do Documento Técnico n.391 do Banco Mundial confeccionado por Maria Dakolias (1996). As pesquisas de Garavito (2011) articulam a difusão do Estado de Direito e Reforma do Poder Judiciário enquanto prioridades do projeto neoliberal. 0 autor analisa os conflitos decorrentes de situações envolvendo as elites locais, com seus distintos projetos, acerca da definição de qual deve ser o papel dos tribunais nas democracias latino-americanas. 
Isso não foi diferente no tocante às questões ambientais. 0 empenho do Banco Mundial (BIRD), do Fundo Monetário Internacional (FMI) e da Organização Mundial do Comércio (COM)... na "construção da geopolítica do desenvolvimento sustentável”, é revelado por Gonçalves (2006). Este afırma que “[...] o mercado, se operado livremente, é o único meio concebível de alcançar o desenvolvimento sustentável, expressão que, cada vez, faz parte do mainstream." (GONÇALVES, 2006, p. 301-302). E essas instituições internacionais idealizam o funcionamento do mercado a que chamam de estratégias win or win, aliás, a mesma que fundamenta os dispositivos descritos acima sobre os "mecanismos alternativos de solução de conflitos”, designados ADR (“Alternativa Dispute Resolutions"), instituídos no Brasil com a reforma do Código de Processo Civil.

No Brasil, identificamos (SHIRAISHI NETO, 2017) no deslocamento das políticas ambientais (de um modelo que enfatizava o desenvolvimento sustentável para outro envolvendo a gestão da natureza) o papel de várias agências de cooperação internacional [Organização das Nações Unidas (ONU), Organização das Nações Unidas para a Alimentação e Agricultura (FA0), Programa das Nações Unidas para o Meio Ambiente (PNUMA) e Comissão Econômica para a América Latina e o Caribe (CEPAL)]. Demonstramos que os estudos (diagnósticos, relatórios...) realizados por essas agências contaminaram as definições das políticas ambientais nas últimas décadas, impondo as reformas legais, tal como foi o caso da política destinada à proteção do conhecimento tradicional associado à biodiversidade e à justa e equitativa repartição de benefícios.

\section{A Lei $13.123 / 2015$ sob Orientação do Protocolo de Nagoya: o conhecimento tra- dicional associado à biodiversidade como objeto/mercadoria}

Todos têm o direito ao meio ambiente ecologicamente equilibrado, bem de uso comum do povo e à sadia qualidade de vida, impondo ao poder público e à coletividade o dever de defendê-lo e preservá-lo para as presentes e futuras gerações. (caput do art. $225 \mathrm{CF} / 88$ - grifos nossos).

Depreende-se do conteúdo do caput do art. 225, que a proteção da natureza se vincula à manutenção do equilíbrio ecológico, à sadia qualidade de vida e à equidade intergeracional, daí o seu caráter de bem jurídico fundamental. Autores (SILVA, 2002; BENJAMIN, 2005) ressaltam que a Constituição de 88 abandonou o "paradigma liberal”, edificando outro modelo, caracterizado por uma preocupação lastreada nas dimensões social e ambiental.

No contexto do sistema de proteção organizado pela Constituição de 88, destacamos a radicalidade da posição de Antônio Herman Benjamin. Para ele, a Constituição de 88 se afastou de uma postura "antropocêntrica” (que aparta a sociedade da natureza) em prol de uma outra, "biocêntrica"19,

18. Essa posição em muito se aproxima das discussões que acontecem no Equador e Bolivia sobre os direitos da natureza. A expressão "giro biocêntrico" foi utilizada por Gudynas (2014) para analisar os processos inscritos no contexto do Novo Constitucionalismo Latino-Americano. 
que não faz distinção entre os dois domínios, tutelando a vida na sua totalidade (BENJAMIN, 2005, p.273).

0 certo é que a Constituição brasileira de 1988 construiu uma nova representação da natureza, talvez mais adequada às necessidades da nossa sociedade, reconhecidamente plural e complexa.

Apesar desse sistema de proteção da natureza, a partir da década de 1990, observam-se sucessivos deslocamentos da política ambiental brasileira em favor de um modelo que tem a natureza como recurso estratégico (SHIRAISHI NETO, 2017). As leis aprovadas, produtos de um incessante trabalho promovido pelas instituições f1nanceiras e agências de cooperação internacional, sintetizam essas transformações.

Os discursos avaliadores das novas leis ambientais professam tornar as relações “claras", “eficientes”, “seguras”, portanto, mais "lucrativas”... tal é a finalidade das mudanças. A “melhoria da gestão”, que alicerça esse discurso, fundamentado nos ideais do livre mercado, inaugura um novo período de suposta proteção da natureza no Brasil.
Tais proposições, expressando lógica e racionalidade próprias diante de interesses econômicos concretos, quando aplicados às questões ambientais geram contradições, a exemplo da Lei 13.123/ 2015, pois os povos e comunidades tradicionais, destinatários diretos da Lei, conformam distintas "axiologias" e "temporalidades" ignoradas pelo "tempo do direito".

No caso do direito ambiental brasileiro, as reformas aprofundam a visão antropocêntrica, questionada por Benjamin (2005), distanciando a sociedade da natureza, já que a sua proteção fica condicionada à utilidade e ao valor econômico a ela atribuído, esse era o entendimento formado pela maioria dos deputados e senadores que aprovaram o Projeto de Lei.

A época, o relator designado na Comissão Especial ${ }^{19}$, deputado Alceu Moreira da Silva, do PMDB-RS, representante da Frente Parlamentar da Agropecuária (FPA) ${ }^{20}$, literalmente comandou a aprovação da proposta apresentada pelo governo, na forma de um Substitutivo ${ }^{21}$, não permitindo alterações que pudessem modificar o seu con-

19. Em razão da distribuição a mais de três comissões de mérito (Comissões de Direitos Humanos e Minorias; Relações Exteriores e de Defesa Nacional Desenvolvimento Econômico, Indústria e Comércio; Trabalho, de Administração e Serviço Público; Ciência e Tecnologia, Comunicação e Informática; Meio Ambiente e Desenvolvimento Sustentável; Finanças e Tributação; e Constituição e Justiça e de Cidadania), foi determinado a criação de Comissão Especial para apreciar a matéria encaminhada pelo governo, conforme art. 34, II, do RICD.

20. Recentemente, o deputado assumiu o comandando da Frente Parlamentar da Agropecuária (FPA), em substituição a deputada Tereza Cristina, que foi nomeada para o Ministério da Agricultura, Pecuária e Abastecimento (MAPA). Na ocasião, Alceu Moreira discursou, afırmando que: "A agropecuária brasileira nunca foi contra o meio ambiente, contra os indígenas. As pautas são complementares e não antagônicas. Temos de fugir desses conflitos e encontrar soluções por meio de políticas públicas sólidas que deem segurança a todos." (ALCEU Moreira é eleito presidente da FPA. Disponível em https://agencia.fpagropecuaria. org.br/2018/12/11/alceu-moreira-e-eleito-presidente-da-fpa/. Acesso em 19/03/2019).

21. 0 parecer foi proferido em plenário pelo relator - já que a Comissão Especial não se reuniu, que concluiu pela aprovação do Projeto de Lei, na forma do Substitutivo apresentado, e pela rejeição de todas as 
teúdo original, contra protestos do PSOL, PCdoB e setores do PT.

A derrota nas votações revelou a força da bancada ruralista na Câmara: "É uma vergonha a votação que nós estamos fazendo aqui. 0 senado foi muito melhor nessas questões. Isso foi uma 'tratoragem' imposta pela bancada ruralista, indignouse o deputado Ivan Valente, do PSOL-SP."22

A manifestação do senador Jorge Viana, do PT-AC, relator da proposta na Comissão de Meio Ambiente ${ }^{23}$, a respeito da forma de como foi conduzido o Projeto de Lei, que resultou na Lei 13.123/ 2015, expressa o sentimento de um grupo de ambientalistas que pouco pode fazer diante da convergência de interesses econômicos das industrias química, alimentícia, cosméticos e agropecuária, todos eles preocupados em expandir os seus mercados e melhorar a competividade à custa do acesso a sociobiodiversidade brasileira. Para isso, criaram obstáculos, exceções legais, que impossibilitam a justa e equitativa repartição dos benefícios decorrentes do conhecimento tradicional associado à biodiversidade, em contrariedade ao Protocolo de Nagoya.

Para um país megadiverso, que tem 20\% da biodiversidade do planeta, não ter uma legislação que contemple o acesso à biodiversidade, é o pior dos mundos", disse o senador Jorge Viana (PT-AC), relator do projeto de lei no Senado. "É uma pena que a Câmara tenha desperdiçado a oportunidade de termos uma lei melhor do que a que está saindo. ${ }^{24}$

\section{Continua o senador. Para ele:}

esta é a lei mais importante depois do Código Florestal”, que agora segue para sanção presidencial. 0 movimento socioambiental acusa o desequilíbrio da proposta, que foi construída pelas associações que representam a indústria mas deixaram de lado, dizem, as comunidades tradicionais.

emendas de n.01 a 220; é importante registrar a ínfıma participação dos deputados nas discussões. A reportagem publicada pela Agência Gestão CTEtI lembra: "As alterações ao texto original, apresentado pelo Governo Federal, foram propostas por 20 deputados.” (DEPUTADOS apresentam 137 emendas ao projeto de Acesso ao Patrimônio Genético. Brasília: Agência Gestão CTAt - 18/08/2014. Disponível em http:// portal.abipti.org.br/deputados-apresentam-137-emendas-ao-projeto-de-acesso-ao-patrimonio-genetico/. Acesso em 19 de março de 2019). 0 relator da proposta, deputado Alceu Moreira (PMDB-RS), acatou 12 das 23 emendas apresentadas pelo Senado Federal, sendo que a proposta original pouco foi modificada. 22. PLENÁRIO da Câmara aprova Lei de Acesso ao Patrimônio Genético. Brasília: Agência Gestão CTEt - 28/04/2015. Disponivel em https://portal.abipti.org.br/plenario-da-camara-aprova-lei-de-acesso-ao-patrimonio-genetico/ . Acesso em 19 de março de 2019.

23. No Senado, a proposição (PLC 02, de 2015) foi distribuída inicialmente a três Comissões (Constituição, Justiça e Cidadania; Assuntos Econômicos; e Meio Ambiente, Defesa do Consumidor e Fiscalização e Controle, posteriormente, em virtude de um requerimento do senador Acir Gurgacz, do PDT-R0, a matéria foi examinada pela Comissão de Ciência, Tecnologia, Inovação, Comunicação e Informática e Agricultura e Reforma Agraria. Lá, no Senado, foram realizadas duas Audiências Públicas, com a participação, principalmente, de órgãos do governo que elaboraram a minuta do Projeto de Lei.

24. HOUVE retrocesso na biodiversidade, critica WWF. Rio de Janeiro: Jornal Valor Econômico, 29/04/2015. Disponivel em https://www.valor.com.br/politica/4026720/houve-retrocesso-na-biodiversidade-criticawwf. Acesso em 19 de março de 2019. 
Apesar de serem tidas como necessárias, já que se mostram "mais eficientes" do ponto de vista da "gestão" da natureza, observase que as reformas das leis podem ser mais prejudiciais que benéficas, pois desconhecem os "modelos de natureza", que representam distintos usos e apropriações. Portanto, essas novas leis ambientais devem ser analisadas de forma criteriosa, já que os seus resultados pouco expressam a ideia primeira de preservação e do cuidado com a natureza inscritos no texto constitucional de 1988.

A Convenção sobre a Biodiversidade Biológica (CDB) e o Protocolo de Nagoya se inserem no esquema analítico, que objetiva construir uma "unidade legal" global, de maneira a atender os interesses do capital em promover a livre circulação de pessoas, bens e serviços. Contudo, não ignoramos a relevância da Convenção sobre a Biodiversidade Biológica (CDB) em, diante da liberdade de acesso aos recursos naturais - tidos anteriormente como "patrimônio comum da humanidade", reconhecer a soberania dos países sobre os seus recursos genéticos (CUNHA, 2009), combatendo, assim, a chamada "biopirataria" (AUBERTIN e FILOCHE, 2011).

Segundo essas autoras, os países pobres ou em desenvolvimento, em sua maioria considerados ricos em recursos genéticos, denominados “megadiversos", eram prejudicados economicamente diante de sua incapacidade industrial e tecnológica em desenvolver produtos oriundos da biodiversidade, mas também movidos por uma "crença” de que há um mercado para os recursos genéticos, capazes de alimentar uma nova economia baseada na preservação sociobi- diversidade (AUBERTIN e FILOCHE, 2011)

Contudo, a garantia formal da soberania sobre os recursos genéticos - hoje, "patrimônio genético do país -, bem de uso comum do povo" (Art. $1^{\circ}$ da Lei 13.123) não expressa per si a efetiva soberania do país. A Lei 13.123, fundamentada na CDB e no Protocolo de Nagoya, representa uma imposição à regulamentação, pois se direciona a "facilitar" o acesso à sociobiodiversidade do país a pretexto da preservação ambiental e desenvolvimento. Vários elementos identificados na análise sublinham a convergência entre a Lei 13.123 e o Protocolo de Nagoya:

a) patrimônio genético e o conhecimento tradicional se constituem em recursos estratégicos para a preservação ambiental e o desenvolvimento dos países considerados "megadiversos";

b) natureza deve ser preservada enquanto objeto/mercadoria;

c) indiferente aos "modelos de natureza" vividos, um único modelo legal é válido;

d) "crença" de que o mercado é capaz, per si, de regular as relações, objetivando a repartição justa e equitativa dos benefícios derivados do acesso ao conhecimento tradicional; e

e) instituição de um sistema legal que possibilite a defınição segura das titularidades, dos objetos e das formas de contrato tendo em vista as necessidades do mercado de livre disposição e circulação dos recursos.

Para Laymert Garcia dos Santos (2003), o capitalismo logrou a instituição de "novos padrões” para lidar com a biodiversidade brasileira, uma vez que conseguiu conciliar a sua expansão aos interesses ecológicos ${ }^{25}$

25. Aubertin e Filoche destacam: "[...] and so it was that a comercial and industrial agrément was hailed as a victory for biodiversity." (AUBERTIN e FILOCHE, 2011, p.51). 
"[...] a riqueza da biodiversidade brasileira vem sendo dilapidada para promover a integração da região amazônica na economia de mercado, através de um desenvolvimento predatório." (SANTOS, 2003, p. 23). Em resumo, a CDB e o Protocolo de Nagoya apresentam uma mudança de paradigma, que tem postulado a natureza (os recursos genéticos e o conhecimento tradicional) como objeto, fonte de matéria prima, condicionando sua tutela ao valor econômico a ela atribuído.

Ao formular uma vigorosa crítica a esse processo que denomina de pilhagem da natureza, Vandana Shiva (2001) denuncia: enquanto no período colonial, a violência da pilhagem provinha do uso da força, agora, ela emana das leis.

Os termos utilizados para justificar a necessidade da edição da Lei 13.123 (e consequente revogação da MP 2.186-16), expressam ideologias próprias, produzidas e difundidas por instituições e agências vinculadas a interesses econômicos de um "poder global difuso".

0 Projeto de Lei 7.735/2014 (que originou a Lei 13.123/2015) foi proposto com uma dupla finalidade: revogar a Medida Provisória 2.186-16, de 23 de agosto de 2001; e conformar a Lei as diretrizes de conteúdo do Protocolo, já que as leis, decretos e regulamentos em vigor "[...] não atendem adequadamente a demanda conhecida e potencial para o uso da sociobiodiversidade no Brasil”, bem como a necessidade de "[...] o país precisa estar preparado para responder a esses novos compromissos que estão sendo assumidos em âmbito internacional." (grifos nossos). ${ }^{26}$

Os argumentos que justificavam o PL estariam alinhados ao que foi designado de "novos paradigmas", já que o momento demanda a instituição de "sistemas modernos” para facilitar o acesso e uso econômico da sociobiodiversidade. A revisão da MP, portanto, se fazia necessária, mediante os imperativos econômicos de maior "clareza” e "segurança” jurídica aos interessados, gerando, assim, supostamente, benefícios à toda sociedade brasileira ${ }^{27}$.

Para além dos argumentos técnicos assinalados, está em jogo a exploração econômica da sociobiodiversidade brasileira, tida como "ouro verde". Aliás, essas ideias, que associam a preservação à exploração, orientam o rol de argumentos manejados para justificar a regulamentação jurídica de bens da natureza, a exemplo dos recursos hídricos, florestais, terra... (SHIRAISHI NETO, 2017), a despeito dos problemas gerados, ditados por uma ordem que promove a construção de uma homogeneidade jurídica global ${ }^{28}$.

26. Inteiro teor do Projeto de Lei 7735/2014 (Cf. informação do site http://www2.camara.leg.br/proposicoesWeb/fichadetramitacao?idProposicao=619150. Acesso 20 de fevereiro de 2018).

27. Inteiro teor do Projeto de Lei 7735/2014 (Cf. informação do site http://www2.camara.leg.br/proposicoesWeb/fichadetramitacao?idProposicao=619150. Acesso 20 de fevereiro de 2018).

28. Uma situação ilustrativa dos problemas gerados por essa racionalidade é a "guerra da água”, em Cochabamba, na Bolívia. A propósito, recomendamos o vídeo “Abuela Grillo”. Disponível em https://www. youtube.com/watch?v=AXz4XPuB_BM. Acesso em 15 de fevereiro de 2018. 0 vídeo "Planeta en venta" (Disponivel em https://vimeo.com/23987980. Acesso em 15 de fevereiro de 2018) retrata a expansão econômica do capital pelo mundo. 0 documentário expõe a aquisição de terras na África por empresas e governos estrangeiros. 
Tais termos e expressões tidos como parte de um "novo paradigma" - que está a modelar as relações sociais e econômicas -, em muito se aproximam daqueles utilizados em outros projetos e programas em curso no país, como o Programa de Reforma Agrária instituído no período do governo Fernando Henrique Cardoso, denominado "Cédula da Terra" (SAUER, 2004) e a Reforma do Poder Judiciário no Brasil, já referido. Acompanhando a seara das reformas ditadas, o Protocolo de Nagoya incorpora instrumentos sugeridos pelos experts da reforma poder judiciário, como os mecanismos consensuais de resolução de conflitos (alínea “c”, do art.18), tidos como mais benéficos à sociedade globalizada.

A semelhança dos argumentos contidos em cada um dos programas, que expressam um consenso em torno do uso de termos e expressões, salientamos a potência das ideias produzidas e difundidas e os interesses econômicos travestidos, que corroem a soberania do país no tocante à capacidade de preservar a sua sociobiodiversidade.

0 paradoxo está: ao mesmo tempo em que o Estado detém a soberania sobre os recursos genéticos, não tem o poder de livremente exercê-la, está pois condicionado a um "padrão internacional" replicado a nível global $^{29}$. Observa-se, contudo, que esse "padrão internacional” não pode desconhecer ou mesmo violar direitos institucionalmente reconhecidos pelo Brasil, sobretudo, aqueles relacionados aos "povos indígenas" e "comunidades locais", tal como preceitua o próprio Protocolo de Nagoya, que deve ser interpretado à luz da Convenção 169 da OIT.

Ainda que as leis de proteção da natureza se fundamentem nos "novos paradigmas”, essas não podem se afastar dos princípios contidos na Constituição de 88 [quais sejam: "pluralidade", “isonomia", "justiça social” e "dignidade" (arts. $1^{\circ}$ e $\left.3^{\circ}\right)$ ], que densificam, tonificam e atribuem conteúdos, significados e sentidos à elaboração dos novos dispositivos legais e as decisões judiciais emanadas do Poder Judiciário.

\section{Considerações Finais}

Certamente, a globalização do direito vem reestruturando o campo jurídico no Brasil. A unificação do campo através da homogeneização jurídica se impõe pelo mundo a partir de uma experiência particular, a do direito norte-americano. Esse movimento, constituído de estratégias do imperialismo norte-americano, se vincula às necessidades de transformar os indivíduos e a sociedade que dão forma e direção ao Estado.

Em um contexto de unificação do campo jurídico, a pesquisa destacou o papel das instituições financeiras (BIRD, FMI) e agências de cooperação internacional (ONU, FA0, PNUMA, CEPAL), na produção e difusão de um discurso que determina reformas jurídicas (estruturas, leis e procedimentos) para o suposto funcionamento do direito na economia globalizada. Mais precisamente, a proteção dos direitos de propriedade privada à livre circulação de bens, serviços, pessoas e do próprio capital.

29. Sob a mesma ordem internacional, países como a Bolivia e o Equador tratam determinados temas de forma particular. No tocante ao conhecimento tradicional associado à biodiversidade a Constituição de 2008 do Equador é detentora de um conteúdo próprio (MARTINEZ, 2015, p.39-43). 
No tocante às questões relacionadas ao acesso ao conhecimento tradicional e à justa e equitativa repartição de benefícios, objeto do artigo, fica claro que a CDB e Protocolo de Nagoya (ambos da ONU) determinaram os conteúdos da Lei 13.123/2015, que reformou a MP 2.186-16/ 2001, embora importe sublinhar os agudos conflitos decorrentes da aplicabilidade da MP, também estabelecida de forma autoritária.

A despeito dos discursos que justificam a necessidade de um novo regulamento legal sobre o conhecimento tradicional e a justa e equitativa repartição dos benefícios, não se trata de objetivar os interesses da sociedade de modo a garantir um "meio ambiente ecologicamente equilibrado" para uma "sadia qualidade de vida", tal como dispõe o caput do art. 225 da CF.

Trata-se, ao contrário, de uma nova forma, em que as relações dos interesses econômicos privados (e de países) se reconfiguram, determinando novos conteúdos à natureza. Ao condicionar a proteção da natureza à sua utilidade econômica, a Lei 13.123/ 2015 nega a multiplicidade de situações que envolvem usos vinculados aos distintos "modelos de natureza" vividos pelos mais variados povos e comunidades tradicionais no Brasil.

A Lei 13.123/ 2015, assim como outras tantas leis, expressa, desta forma, a concretização de outro projeto de sociedade, hoje sacralizado com o golpe parlamentar, jurídico e midiático que destituiu uma presidente legalmente eleita.

\section{Referências}

ALEXANDER, M. A Nova Segregação. Racismo e encarceramento em massa. São Paulo: Boitempo, 2017.

ARNAUD, A-J. o Direito entre Modernidade e
Globalização. Lições de Filosofia do Direito e do Estado. Rio de Janeiro: RENOVAR, 1999.

AUBERTIN, C; FILOCHE, G. The Nagoya protocolo $n$ the use of genetic resource: one embodiment of na endless discussion. Sustentabilidade em Debate, v.2, n.1, p.51-64, jan/jun 2011.

ARAÚJO, A. V. Acesso a Recursos Genéticos e proteção aos Conhecimentos Tradicionais Associados. In: LIMA, A. (org.). 0 Direito para o Brasil Socioambiental. Porto Alegre: Fabris, 2002. p. 85-99.

BENJAMIN, A. H. O Meio Ambiente na Constituição Federal de 1988. In: KISHI, S. A. S. et. al. (Orgs.). Desafios do Direito Ambiental no Século XXI. Estudos em homenagem a Paulo Affonso Leme Machado. São Paulo: Malheiros Editores, 2005. p. 363-398.

BERCOVICI, G. Constituição e Estado de Exceção Permanente. Rio de Janeiro: Azougue Editorial, 2004.

BERCOVICI, G. Soberania e Constituição: para uma crítica do constitucionalismo. São Paulo: Quartier Latin, 2008.

BONILLA MALDONADO, D. Los Mandarines del Derecho. El trabajo jurídico pro Bono en perspectiva comparada. In: Los Mandarines del Derecho: transplantes jurídicos, analisis cultural del derecho y trabajo pro Bono en America Latina. Bogotá: Siglo del Hombre Editores y Universidad de los Andes, 2017.p. 29-133.

BOURDIEU, P. A força do direito. Elementos para uma sociologia do campo jurídico. In: BOURDIEU, P. 0 Poder Simbólico. Lisboa: Difel, 1989. p.209254.

BOURDIEU, P. Contafogos 2: por um movimento social europeu. Rio de Janeiro: Zahar Ed., 2001.

BOURDIEU, P.; WCQUANT, L. Sur les Ruses de la Raison Imperialiste. Actes de la Recherche en Sciences Sociales, 121/122, p. 109-118, mars 1998.

CARBONELL, M.; VÁZQUEZ, R. Presentación. In: CARBONELL, M.; VÁZQUEZ, R. La Globalizacion y el Orden Jurídico. Reflexiones Contextuales. Bo- 
gotá: Universidad Externado de Colombia, 2007. p. 09-17.

CUNHA, M. C. da. "Cultura" e Cultura: conhecimentos tradicionais e direitos intelectuais. In: Cultura com Aspas e outros ensaios. São Paulo: COSACNAIFY, 2009. p.311-373.

DERANI, C. Patrimônio Genético e Conhecimento Tradicional Associado: considerações jurídicas sobre seu acesso. In: LIMA, André (org.). 0 Direito para o Brasil Socioambiental. Porto Alegre: Fabris, 2002. p. 145-167.

DELAZAY, Y. 0 Big- Bang e o Direito: Internacionalização e Reestruturação do Espaço Legal. In: FEATHERSTONE, M. (Coord). Cultura Global: Nacionalismo, globalização e modernidade. Petropolis: Editora Vozes, 1999. p. 295- 310.

DELAZAY, Y; GARTH, B. The Internacionalization of Plalace Wars. Lawyers, Economistic, and the Contest to Transform Latin American Studies. Chicago: The University os Chicago, 2002.

DELAZAY, Y.; GARTH, B. Legitimanting the New Legal Orthodoxy. In: Global Prescriptions. The Production, Exportation, and Importation of a New Legal Orthodoxy. USA: Michigan Press, 2005. p. 306-334.

DELAZAY, Y; TRUBEK, D. M. A Restruturação Global e o Direito. In: FARIAS, José Eduardo (org.). Direito e Globalização Econômica: implicações e perspectivas. São Paulo: Malheiros Editores, 2010. p.29-80.

ESCOBAR, A. 0 lugar da natureza e a natureza do lugar: globalização ou pós-desenvolvimento? In: LANDER, Edgard (org.). A colonialidade do saber: eurocentrismo e ciências sociais perspectivas latino - americanas. Argentina: CLACSO, 2005. p.6379.

FARIA, J. E. 0 Direito na Economia Globalizada. São Paulo: Malheiros, 2002.

GONÇALVES, C. W. P. A Globalização da Natureza e a Natureza da Globalização. Rio de Janeiro: Civilização Brasileira, 2006.

GUDYNAS, E. Derechos de la naturaleza y poli- ticas ambientales. La Paz: Plural editores, 2014.

MARTINEZ, E. La Naturaleza, los conocimientos tradicionales y la Constitución del Ecuador. In: ACOSTA, A. ; MARTINEz, E. (Orgs.). Biopiratería. La biodiversidad y los conocimientos ancestrales en la mira del capital Quito: Abya Ayala, 2015. p.35-45

MIAILLE, M. Une Introduction Critique au Droit. Paris: François Maspero, 1977.

MOREIRA, E. Conhecimento Tradicional e a Proteção. T e C Amazônia, ano v, n.11, p.33-41, jun. 2007.

NADER, L. Harmonia Coercitiva. A economia política dos modelos jurídicos. Revista Brasileira de Ciências Sociais, n.26, ano 9, p. 18-29, outubro de 1994.

NOBRE, M. Apontamentos sobre a pesquisa em direito. Novos Estudos, n. 66, p.145-154, julho de 2003.

OLIVEIRA, F. de. Aproximações ao enigma: o quer dizer desenvolvimento local? In: SPINK, Peter et. al. (Orgs.). Novos contornos da gestão local: conceitos em construção. São Paulo, Pólis; Programa Gestão Pública e Cidadania/EAESP/FGV, 2002. p.11-31.

PORTER, Caro et. al. (Orgs.). Comentários a uma Sentença Anunciada: o processo Lula. Bauru: Canal 6 Editora, 2017.

RANCIERE, J. Le príncipe d'insécurité. In: Chroniques des Temps Consensuels. Paris: Éditions Du Seuil, 2005. p.163-167.

RODRIGUES GARAVITO, C. Toward a Sociology of the Global Rule of Law Field. Neoliberalism, neoconstitucionalism, and the contest over judicial reform in Latin America. In: DELAZAY, Y; GARTH, B. (Eds). Lawyers and Rule of Law in an Era of Globalizacion. USA: Routledge, 2011. p. 156-182.

SANTILLI, J. Socioambientalismo e Novos Direitos. Proteção jurídica à diversidade biológica e cultural. São Paulo: Peirópolis, 2005.

SANTOS, B. de S. La Globalizacion del Derecho. 
Los nuevos caminhos de la regulación y la emancipación. Bogotá: Universidad Nacional del Colombia/ Faculdad de Derecho, Ciencias Sociales y Politicas/ ILSA, 1999.

SANTOS, B de S; GARAVITO, C. R. (Orgs.). El derecho y la globalizacion desde abajo: hacia una legalidad cosmopolita. Barcelona: Anthropos; Mexico: UAM-Cuajimalpa, 2007.

SANTOS, L. G. dos. A Encruzilhada da Política Ambiental Brasileira. In: Politizar as novas tecnologias: o impacto sócio-técnico da informação digital e genética. São Paulo: editora 34, 2003. p.15-48.

SAUER, S. A terra por uma cédula: estudo sobre a reforma agrária de mercado. In: MARTINS, M. D. (Org.). 0 Banco Mundial e a Terra: ofensiva e resistência na AL, África e Ásia. São Paulo: Viramundo, 2004. p.40-60.

SCHWARZC, L. M. O espetáculo das raças: cientistas, instituições e questão racial no Brasil - 18701930. São Paulo: Cia. das Letras, 1993.

SHIRAISHI NETO, J. 0 campo jurídico em Pierre Bourdieu: a produção de uma verdade a partir da noção de propriedade privada nos manuais de direito. Revista Sequencia, n.56, pp.83-100, junho de 2008.

SHIRAISHI NETO, J. Notas sobre o Processo de Reforma do Poder Judiciário: mais resoluções, menos direitos - o consenso como medida de eficiência de atuação do Poder Judiciário. In: RAMOS, P. R. (Org.). Direito e Instituições do Sistema de Justiça. São Luís: EDUFMA 2015, p. 139-257.

SHIRAISHI NETO, J. Globalização do Direito: novos conteúdos à natureza. Revista de Direito Ambiental Internacional, ano VI, n.17, p. 117-140, maio/agosto de 1017.

SHIRAISHI NETO, J; DANTAS, F. A. de C. A "Commoditização" do Conhecimento Tradicional. Notas sobre o processo de regulamentação jurídica. In: ALMEIDA, A. W. B. de. (Org.). Conhecimento Tradicional e biodiversidade: normas vigentes e propostas. $2^{\circ}$ ed. Manaus: UEA edições, 2010. p. 57-83.
SHIVA, V. Biopirataria. A pilhagem da natureza e do conhecimento. Petrópolis: Editora Vozes, 2001.

SILVA, J. A. da. Direito Ambiental Constitucional. $4^{\circ}$ ed. São Paulo: Malheiros, 2002.

Reportagens, Documentos, Vídeos...

Abuela Grillo. Disponivel em https://www.youtube.com/watch?v=AXz4XPuB BM. Acesso em 15 de fevereiro de 2018.

ALCEU Moreira é eleito presidente da FPA. Disponível em https://agencia.fpagropecuaria.org. br/2018/12/11/alceu-moreira-e-eleito-presidenteda-fpal. Acesso em 19/03/2019).

BRONZATTO, Thiago. Elas fizeram um rapa: uma leva de escritórios que acabam de chegar ao país já contratou mais de 60 advogados de bancas tradicionais. Em jogo, um mercado disputado que movimenta 3 bilhões de reais por ano. Revista Exame, n.12, ano 44, junho de 2010.

DEPUTADOS apresentam 137 emendas ao projeto de Acesso ao Patrimônio Genético. Brasília: Agência Gestão CTEt - 18/08/2014. Disponivel em http://portal.abipti.org.br/deputados-apresentam137-emendas-ao-projeto-de-acesso-ao-patrimonio-genetico/. Acesso em 19 de março de 2019.

$13^{\circ}$ Emenda. Disponivel no site oficial da NETFLIX. Acesso em: 26 de fevereiro de 2018.

DAKOLIAS, Maria. O Setor Judiciário na América Latina e no Caribe. Elementos para Reforma. Washington: Banco Mundial, 1996. (Documento Técnico n. 319).

HOUVE retrocesso na biodiversidade, critica WWF. Rio de Janeiro: Jornal Valor Econômico, 29/04/2015. Disponivel em https://www.valor. com.br/politica/4026720/houve-retrocesso-nabiodiversidade-critica-wwf. Acesso em 19 de março de 2019.

MARTINS, Rodrigo. Os Políticos de Toga. 0 julgamento de Lula é a expressão máxima da Justiça politizada, a retirar do povo o poder de decidir sobre o seu próprio destino. Revista Carta Capital, 
n.987, pp.18-23, 24 de janeiro de 2018.

MINISTÉRIO PÚBLICO FEDERAL. Recomendações. Brasília, 25 de junho de 2015. (Referência: IC 1. 16.000.001457/2015-19).

NASSIF, Luis. Como os EUA passaram a controlar a Petrobras e a JBS, 2017. Disponivel em https:// jornalggn.com.br/noticia/como-os-eua-passaram -a-controlar-a-petrobras-e-a-jbs. Acesso em: 13 de fevereiro de 2018.

PLENÁRIO da Câmara aprova Lei de Acesso ao Patrimônio Genético. Brasília: Agência Gestão CTEI - 28/04/2015. Disponivel em https://portal.abipti. org.br/plenario-da-camara-aprova-lei-de-acesso -ao-patrimonio-genetico/. Acesso em 19 de março de 2019.

TERRA de Direitos; Via Campesina Brasil; Movimento dos Pequenos Agricultores; Movimento de Mulheres Camponesas; GT - Biodiversidade da Articulação Nacional de Agroecologia; Instituto Socioambiental - ISA. Nota Técnica Jurídica Sobre a Regulamentação da Lei 13.123/2015 sobre Acesso ao Patrimônio Genético, aos Conhecimentos Tradicionais Associados e Repartição de Benefícios. Brasília, 20 de outubro de 2015. 33p.

PLANETA en venta. Disponivel em https://vimeo. com/23987980. Acesso em: 15 de fevereiro de 2018.

PROJETO de Lei 7735/2014. Disponível em http:// www2.camara.leg.br/proposicoesWeb/fichadetra-

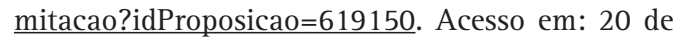
fevereiro de 2018. 
RESUMO

Para atender os interesses de um "poder global difuso", os países ricos em biodiversidade passaram a reformar suas leis de proteção da natureza, já que ela é tida como "vantagem comparativa" em relação aos demais países. 0 direito cumpre um papel estratégico nesse cenário, ao construir uma unidade global dos dispositivos, "homogeneizando" estruturas, leis e procedimentos; e legitimando essa nova ordem. No Brasil, as leis de proteção da natureza têm sido reformadas, decompondo o seu conteúdo jurídico. Este artigo objetiva analisar a lei 13.123/2015, que se encontra inserida na lógica denominada "globalização do direito americano”. A pretexto da necessidade de reformar a medida provisória 2.186/2001, aquela lei modificou a proteção, o acesso e a repartição dos benefícios. A metodologia se baseou no levantamento e análise de dados de fontes secundárias, como documentos e tratados - especificamente: a Convenção sobre a Diversidade Biológica, o Protocolo de Nagoya, e o projeto da referida lei.

\section{PALAVRAS-CHAVE}

Conhecimento tradicional. Biodiversidade. Protocolo de Nagoya. "Globalização do direito americano”. Pilhagem da natureza.

\section{ABSTRACT}

In order meet the interests of a "diffuse global power”, biodiversity-rich countries have reformed their nature protection rights, as it is seen as a "comparative advantage" compared to other countries. The law plays a estrategic role in this scenario, by building a global unit of devices, "homogenizing" structures, righs and procedures; and legitimizing this new order. In Brazil, nature protection right have been reformed, breaking down their legal contente. This article aims to analyze right $13.123 / 2015$, which is inserted in the logic called "globalization of american law". Under the pretext of the need to reform provisional measure 2.186/ 2001, that right modified the protection, acess and distrbution of benefits. The methodology was based on the collection and analysis of data from secondary sources, such as documents and treaties specifically: the convention on biological diversty, the nagoya protocol, and project of said right.

\section{KEYWORDS}

Traditional knowledge. Biodiversity. Protocol of Nagoya. Globalization of american law. Plunder of nature.

Recebido em: 04/06/2018

Aprovado em: 01/04/2019 